\section{ORIGTIAT COMOTULICATIONS.}

\section{TRAUMATIC LESION OF THE EYE.}

By H. HAYNES WALTON, Esq., F.R.C.S., Surgeon to the Central London Ophthalmic Hospital, Assistant Surgeon to St. Mary's Hospital, etc.

Case. Sumary:-Penerration of the Lept Eyebali by a Pabricle of Iron: Pronapge or the Iris, and Chosore or the Pupil, with almost constant Pain in the Organ for aeteral WeEks: Sympathetic INtolkbayce to hight, and considerable Diminotion OF THE POWER of Vision iN THE OTHER Exe: Removal of Cornea and greater Part of Iris prom the wodnded Eye: Fscape or geteral Minute Pieces of oxidised Iron: Cegsation of the long-continued Pain: Coxplete Restoration of the Function of The right Eye. Rexarks.

A HALE powerful man, forty years of age, whilst pursuing his arocation of boiler-making, on the 20th of January, 1853, was wounded in the cornea of the left eye by a piece of the metal which he was chiseling. The iris prolapsed, and the pupil was destroyed. There was not any evidence that the splinter of iron had entered the eye; indeed, appearances were rather against such an occurrence. A few days subsequently, there was an accession of pain, which was ever present during waking hours. Mr. Ernest Elliott, the surgeon of the government establishment at Plymouth to which he belonged, resorted to such measures as were adapted to subdue it; but, finding them ineffectual, and discovering that the other eye evinced symptoms of sympathetic disease, he sent the man to Iondon for $\mathrm{my}$ advice. I saw him on the l6th of March, admitted him into the Central London Ophthalmic Hospital, and made the following note of his case:- "The left eyeball is much inflamed, and apparently disorganised, inasmuch as it is enlarged; and the cornea, which has been divided, is opaque, and bulges. There is not any perception of light. There is pain, sufficiently intense to disturb sleep. The journey has rendered this symptom more severe. In the right eye, there is slight pain with preternatural vascularity of the conjunctiva; considerable intolerance of light, so much that a sheet of white paper cannot be looked at without uneasiness. Vision is not sufficiently perfect to enable him to read the type called English. There is much general prostration. The tongue is foul. He has no appetite."

From some experience in parallel instances, I had not any doubt that the piece of iron, which had impinged on the eye, had passed to its interior, and was yet incarcerated; and, on the conviction of the correctness of such diagnosis, I excised the front of the eyeball to allow of its escape. The greater part of the iris was also excised-a result that was inevitable, at the same time desirable, from the close apposition of this membrane with the cornea, the result of the prolapse. A large amount of what appeared to be aqueous humour escaped. A little of the vitreous humour was lost. The crystalline lens was absent. The eyelids were closed, and retained shut by a strip of plaster; and the patient sent to bed.

On the morning of the second day after the operation, he removed from the corner of the eye with his finger two pieces of iron-rust, about the size of pins' heads. A day later, 2 third bit was cast out.

On the 23rd, my note runs:- "His relief is very decided. There is only occasional pain in the eye; and, from his description of it, it is rather darting than dull. It is probably due to the operation. The surface of the vitreous humour is covered over by a greyish-white pulp-like deposit. The conjunctiva is jet very vascular, and bathed with purulent secretion. The other eye is fast recorering itself, is no lenger red, and can bear bright light much better. He can actually read the Times newspaper." Soon after this, bo left for home; and when I heand from him, on the 8th of April, he stated that all pain had ceased, and that the right eje was daily improving.

REXARKS. While certain affections of the ejo are for the most part consigmed to those who practise for ophthalmic affections on a large scale; and while some may without detriment have their treatment delayed for awhile, there are several which, from their emergency, require prompt attention, and, which all surgical practitioners should be prepared to undertake. Now, mechanical losions constitute one class of those which call for general attention. It is a class of much importance, and susceptible of much practical comment; but $f$ must restrict myself to that division of it under which my case falls (foreign bodies within the eyeball), and at the same time maintain a strict reference to the individual example before me.

The first practical lesson here taught is the impossibility of our being able to determine, from the mere appearance of a wound, or, in the first instance, from the sensations that succeed to it, whether a body has or has not passed into the eyeball. Prolapse of the iris does not afford any indication either way; and it frequently happens that, with the presence of a body, there is not immediately any pain. Perhaps, while the vitreous humour is the resting place, sensitiveness is not manifested; but then even one or the other of the chambers of the eye may not directly resent its lodgment there; yet, on the other hand, there may be pain, immediate, intense, and enduring even for weeks, as the effect of a wound alone. Therefore, in traumatic injury, when we cannot see any foreign substance, after attempting to replace the iris, should there be a probability of the attempt being successful, and adopting such measures as are likely to ward off inflammation, we must patiently abide the result. Even with strong suspicion or positire assurance of a body having entered, should it be out of sight (supposing vision not lost), it would be certain destruction to the eye, and therefore malpractice, to seek guideless for it; and it must be borne in mind, that its presence is not necessarily fatal, as some substances may dissolve, and any may become encysted. But should vision be assuredly destroyed, and the cornea or the sclerotica be extensively wounded, the sooner, by the excision of a part of the eyeball, an exit is afforded for its escape, the better. In any case, after inflammation has set in, attended with much pain, and the means to subdue them have failed, and the eye is evidently disorganised, we ought, I think, to act as if sure of there being a foreign body present; and excision should be practised, as a means of averting suffering, and securing the other eye from a sympathetic attack. Certainly it should be executed directly that sympathetic inflammation sets in. In my patient, the sympathetic attack was unusually early.

From these principles of practice not being generally recognised, many eyes are annually sacrificed. On the value of their observance rest the chief merits of this ro port. For the valuable facts on which they are founded, we are indebted to Mr. Barton (see report by Mr. Crompton, London Medical Gazette, vol. xxi); and the reitoration of them here cannot be superfluous. In seren cases, a fragment of copper cap was driven into the eye; and, from the symptoms, it was not possible to determine whether the cap had entered or not. The eyes not wounded became affected ; loss of vision was threatened. Mr. Barton, suspecting the nature of the cases, excised the cornea, and applied poultices, in the hope that the fragments of copper would escape, and the cause of irritation, with its threatenings on the other eye, would be removed. In all of the number, the copper passed out, and was found either in the coagulum of the wound or in the poultice; and the effect on the other eye was magical.

Now, concerning the manner of operating, I do not consider it immaterial. I suspect that, to be certain of the result we seek, the iris, $i$. e., the greater part of it, should be removed, together with the cornea, or elee it may be an obstacle to the body coming away. Where it is prolapsed 
(and it has been so in all the cases with which I have been concerned), a large portion of it must necessarily be removed. The details of my operation may be thus expressed. After an assistant has retracted the eyelids, I transfix the eornea with a curved cataract noedle, and with a cataract knife cut away the required portion.

69, Bro:k Street, Innover Siquare, Lonton, . Ipril 1\%b3,.

\section{FAILCRE OF VACCINE.}

\section{Ty .J. A. HIN(iESTON, Esi.}

THE frequent failure of vaccination is now so generally admitted, that statistical proofs are not requisite in order to establish its truth. People look upon it as an equal chance, whether those who have been vaccinated shall be able to resist an attack of the small-pox or not, should they be exposel to it; while some go so far as to surmise, hastily and rashly enough, that vaccination is all but useless. A few vote for a return to the old variolous inoculation; and a few, still more inconsiderate, boldly declare themselves in favour of the small-pox itself, as the only and the surest guarantec of their safety. There is, of course, a great deal of exaggeration and misrepresentation in expressions of this sort ; and much more is affirmed against the non-protective agency of vaccine lymph, than, as is usual, a dispassionate inyuiry into all the circumstances of the case will justify or imply. The broad and uridisputed fact of the actual diminution of small-pox since vaccination has been introduced and practised, is alone sufficient to contradict these wild notions, and to refute the vulgar prejudices atloat upon the suliject. Fur, even during an occasional outbreak, the disease is nothing now to what it used to be formerly, when the old inoculation, which is itself not free from risk, was the only obstacle opposed to its incessant and alarming encroachments. At that time, it was a real plague of terrible malignity, whereas it is now a comparatively mild and transient epidemic. 'This well-known fact is a satisfactory answer in favour of the protective influence of vacciuation, whicb, if not universally, is at least extensively serviceahle and effectual.

To medical men, the occasional failure of vaccine lymph presents itself in a very different light from that in which it is viewed by the public at large; and with vaccinators in particular it is a topic of the deepest interest, which they endeavour to explore to the best of their abilities, and in every possible direction. 'The various points of inquiry offered to their notice, mily be reduced to the few following items.

I. A chief cause is the capital oversight on the part of the vaccinator himself, in triusferring lymph from an imperfect pock. 'There is no doult that this oversight or carclessness is a copious source of the quantity of bad lymph in circulation, as well as of the ultimate failure of vaccination as a protective agent. For it is a maxim in vaccinating, never to transfer lymph from a pock in the slightest degrec abnormal, nor from a normal pock in a constitution evidently disordered or unsound; because, if it be so transferred, the inevitable result will be abnormal pocks and inefficient lymph. It is impossible to restore contaminated lymph to its primitive purity; no subsequent cure in its propagation can ever recover its lost or defective virtue. Having once hecome devious or degenerate, it continues to descend both degenerate and devious, until its power lecomes extiuct, and it fails to propagate itself, even in a degenerate form. This glaring fact is so unquestionable, that it is necessary to bring it forward, and place it first and foremost among the causes of the failure of the vaccine lymph.

11. Another main cause of failure is, we must candidly own, carelessness in the act of vaccinating. Not only is the good quality of the lymph used not strictly inquired into at the outset, but, what is more unpardonable, the mode of operating is not exactly performed. There is a right and a wrong way of vaccinating, just as there is a right and a wrong way of amputating, bleeding, or tying an artery. Every surgeon knows the value of performing an operation rightly, and the evil consequences to be apprehended from operating wrongly. It is the same with vaccination, which, in its vital results, takes rank among the capital operations of surgery, and requires, for its proper performance, an intelligence as clear and a hand as dexterous as ever fell to the lot of the best of surgeons. By neglecting, or by not being aware of, the precise way of operating, it happens that so many vaccinations turn out, either eventually or immediately, inefficient. The puncture is made too wide or too deep, or irregular; each of which faults materially affects the shape and character of the vesicle ; or else, if it have been properly performed, and the lymph effectually inserted, it is not punctually watched from day to day throughout its progress. Success demands coustant vigilance. In performing the operation, the cuticle alone must be raised, and the cutis beneath exposed, but not wounded, or wounded as little as possible. The cutting, or rather the scratching, of the cuticle, should be done lightly and delicately, with the least possible irregularity, and over the smallest extent of surface consistent with the application or insertion of the lymph. Its course must be watched and noted on the third, eighth, and fourteenth days in particular; and no case can be pronounced safe, unless erery step in its progress have shown itself to be regular, critical, and complete.

It is rery necessary to point out these causes of failure; first of all, because they are freruent, and seem, in a great measurc, to have lost of late years something of their due weight and importance in the estimation of inedical men.

From the medical pupil never having heen hitherto distinctly educated on the subject of vaccination, he is naturally liable to fall into mistakes through inexperience, which can only be overluoked out of tenderness to his unavoidal,le ignorance, in consequence of his never having been taught, ex officio, how to proceed with scientific precision. But, upon public grounds, inexpertness is inexcusable, and cannot be too severely censured and condemned.

III. Owing to a want of attention to the proper time for taking it, the lymph is transferred too soon or too late, and the obvious consequence is, that unripe or effete lymph is procured and propagated. Of course such lymph is weak, or altogether inefticient. It ought never to be taken a way earlier than the eighth, and sometimes not before the ninth day. At too early a day, it is ichor rather than lymph. Again, it may be taken away too late; that is to say, after the ninth day, when it is becoming purulent, and the vesicle is turning into a pustule. The exact time is eight times twenty-four hours, dating from the hour of the day of vaccinating. The lymph will remain genuine till the ninth day is over, and sometimes even till the tenth ; for occasionally the whole course of the pock is stage hy stage a day after its time: thus, the inflamed point of the third day is delayed till the fourth, and the inflamed halo of the ninth does not reach its climax till the tenth, and, so on. This delay in the progress of the symptoms is regarded as a favourable prognosis; and certainly, in cases disposed to reject the specific action of the virus, the inflammation and vesicle, besides their being abnormal, arise and disappear much too quickly. Lymph taken after the tenth day is universally reprobated; and none but such as are miserably igmorant or indifferent would ever think of transferring it at this late epoch.

Iv. It is advisable never to transfer lymph that has become purulent. A prudent vaccinator never does. Not that pus per se invalidates the lymph any more than blood does ; for it may appear on the ninth day mixed with the genuine lymph: nor would its accidental presence alone weaken or destroy its efficiency : but it indicates more inflammation than is vecessary for the production of the true vesicle, and it moreover signifies the co-existence of an inflammation different in kind from that which produces the genuine lymph. After the tenth day, pus is sure to be 